This item was submitted to Loughborough's Research Repository by the author.

Items in Figshare are protected by copyright, with all rights reserved, unless otherwise indicated.

\title{
Market complexity evaluation to enhance the effectiveness of TRIZ outputs
}

PLEASE CITE THE PUBLISHED VERSION

https://doi.org/10.1007/978-3-030-02456-7_6

\section{PUBLISHER}

Springer Nature Switzerland AG @ IFIP International Federation for Information Processing

\section{VERSION}

AM (Accepted Manuscript)

\section{PUBLISHER STATEMENT}

This is a pre-copyedited version of a contribution published in Cavallucci, D., De Guio, R. and Koziolek, S. (eds). Automated Invention for Smart Industries. Proceedings of the 18th International TRIZ Future Conference (TFC 2018) published by Springer. The definitive authenticated version is available online via https://doi.org/10.1007/978-3-030-02456-7_6.

\section{LICENCE}

CC BY-NC-ND 4.0

\section{REPOSITORY RECORD}

Carrara, Paolo, Davide Russo, and Anna Rita Bennato. 2019. "Market Complexity Evaluation to Enhance the Effectiveness of TRIZ Outputs". figshare. https://hdl.handle.net/2134/35618. 


\title{
Market complexity evaluation to enhance the effectiveness of TRIZ outputs
}

\author{
Paolo Carrara ${ }^{1[0000-0002-0186-3647]}$, Davide Russo ${ }^{1[0000-0001-8000-0147]}$ \\ and Anna Rita Bennato ${ }^{2}$ \\ ${ }^{1}$ Università degli Studi di Bergamo, Dalmine, 24044, Italy \\ paolo.carrara@unibg.it \\ davide.russo@unibg.it \\ ${ }^{2}$ Loughborough University, Loughborough, LE11 3TU, UK \\ a.bennato@lboro.ac.uk
}

\begin{abstract}
In the context of innovation consulting activity, it may happen working in technical fields characterized by a high competitiveness level. Although TRIZ allows reaching innovative ideas in any kind of industry, it does not suggest any tool in order to evaluate the success rate of the invention in the reference market. During the last years, TRIZ got methodological contributes to sharpen the matching between the inventive idea and the actual needs of the market, for example the market potential tool. In order to support TRIZ experts in selecting the best innovation strategy, this paper introduces a new tool for the TRIZ toolbox that takes into account the competitiveness level of the market. Several economics works disclose the correlation between the patent-citation triadic relationships and the presence of dominant positions of few competitors. A patent analysis, focused on triads in patent citation, can inform the TRIZ expert about potential critical situation able to prevent the success of an inventive solution. It can generate an important indicator that helps him in selecting the most promising innovation strategy. The method could be integrated in a classic TRIZ activity, using commercial patent searching tools. The case study shows how to extract this kind of indicator from patent citation environment in Machine Learning field.
\end{abstract}

Keywords: TRIZ, Patent, Patent Thicket, Business Intelligence, Market Structure

\section{Introduction}

Business Intelligence (BI) comprises the strategies and technologies used by enterprises for the data analysis of business information, in order to identify new business opportunities with a competitive market advantage [1-4]. Firms make use of BI strategies to support a wide range of business decisions, which include both operational (i.e. production, and distribution) and technical (i.e. analysis of data) procedure able to improve their own efficiency. In the most recent times, it has been adopted to sup- 
port the product innovation process, minimizing the risk-management decisions about R\&D to the minimum.

In this paper, with the aim to define the structure of the market for innovation, we investigate a large pool of patents extracted from Machine Learning field. It is useful for ranking of the list of product requirement with highest market potential [5].

The market for innovation is particularly characterized by the use of licensing and sale of patents which negotiations could both either promote or prevent the diffusion of a specific technology, affecting firms' incentive to invest in further innovation [6].

In order to take into account the market structure, while ranking the market potential of product/process requirements, we present a new method able to incorporate both characteristics. By using patent counts as a measure of innovation, in this article we propose a procedure which by identifying the presence of possible patent thickets we are able to pinpoint the major market players, and all possible constrains faced by a new innovator entering into the market. [7] (see section 2). Patent thickets are a peculiar characteristic of complex industries. According to the claims made in the patents about both physical and methodological components of the patented product or process it is likely that the ownership of the exclusive intellectual property right can overlap across different economics agents (i.e. firms), preventing their use and creating a proper barrier, especially for the follow-on innovation [7].

Knowing whether or not there is a patent thicket, before starting the problem solving or product innovation activity, is pivotal, as it allows to anticipate and readjust the BI strategy before the launch of the product will occur into the market.

Currently there are no tools able to automatically extract the data necessary to unveil the risk to meet with patent thicket; however, there are strategies based on backward and forward citations with which it is possible to obtain indications regarding any priority relations between patent pairs (or applicant pairs) [8]. Other useful information can be derived from the co-applicant and co-inventors maps, which show collaboration and relationships even between different companies [9] that are assumed to be competition within the same market, unless R\&D cooperation agreements have been signed, and then emerging from the co-patenting measurement.. A simple indication of the presence of patent thickets it is not informative per se, and for that reason the approach we propose would instead suggest the major players in the market, highlighting also the relative structure of the market.

\section{Patent Thicket as Measure for Market Structure}

The patent thicket is "a dense web of overlapping intellectual property rights that a company must hack its way through in order to actually commercialize new technology" [7]. It affects the structure of the market, usually characterized by cumulative or complementary technologies [10], defending against competitors designing around a single patent [11] and/or building hindrances to the innovation [12-16].

A potential new entrant in a specific technological market might be discouraged by the presence of a thicket, simply because of the high cost related to the bargaining 
process which is requested to advance further the innovation. This is even more evident when the market is characterized by few big players which may have a dominant position by owning a large pool of patent, and then conditioning the access to the market. According to the complexity of the patent thickets, the new entrant can be discouraged by the sticky and costly process, and as a result it would not undertake any further investment in the advancement of the new technology [17]. Alternatively, whether the investment takes place by licensing agreements and a new technology is proposed, due to the initial high cost its diffusion will be limited, preventing future advancement in the innovation process. [7]. Galasso and Schankerman [18] show how the presence of patent thickets obstruct follow-on research especially in the complex industries (for example in information and communications technology, electricalelectronics and medical instruments). Once we accept that innovation depends mainly on the paradigm which sees it as a cumulative process upon which new ideas are generated, in Gallini [19] we could find a comprehensive review of the literature which highlights the issues yielded by the presence of patent thickets.

\subsection{A method for identifying patent thicket}

The strategy to measure the density of a patent thicket proposed by von Graevenitz [8] relies on the patent literature cited by the examiner in the search report having kind $\mathrm{X}$ or $\mathrm{Y}$. He uses the triple (see Fig. 1) of applicants involved in mutual blocking citation relationships as a unity of measure of the thicket density. Higher the number of triples, worse the hacking through the thicket.

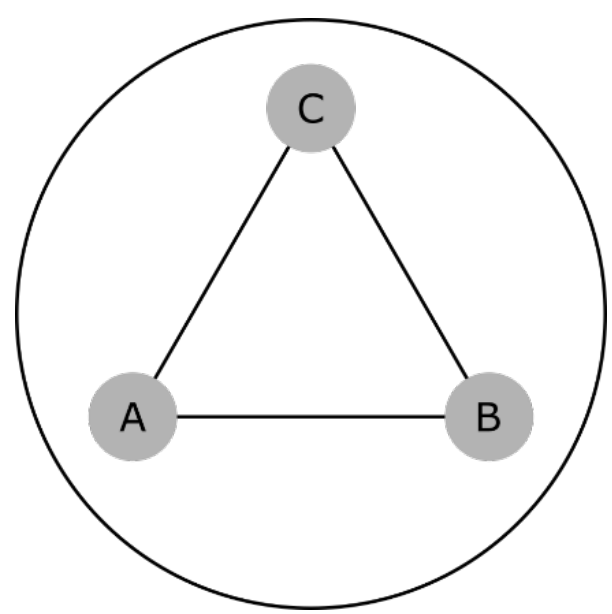

Fig. 1. Schematic presentation of the structure of triple. A, B and C circles identifies the firms involved in triple; the straight lines represent the mutual blocking relationships between firm couples (Souce von Graevenitz [8]) 
Given the complexity of such a type of dimension, it finds some limitation for application to BI analysis. The required skills ranging from IT field, especially SQL language to querying PATSTAT, the statistical DB published by EPO (www.epo.org $\backslash$ searching-for-patents $\backslash$ business $\backslash$ patstat.html), to patent procedural knowledge. This makes hard to reproduce the analyses available in literature.

Furthermore, the method has been proposed in an economical context. It tend to make an economic analysis of the market for the main classes of OST-INPI/FhG-ISI technology nomenclature [20]. The typical dimension of the patent pools used by von Graevenitz is excessively large in order to give an information exploitable by decision makers concerning the reference market structure of a specific technical solution.

Moreover, although the triples count is an interesting method to measure the thicket density, it does not take into account the inner balance (or imbalance) of the patent portfolios, which explains the effective polarization toward one or two competitors in the triple.

In this article, the authors introduce an algorithm able to automatize the triples extraction process in a delimited technology environment. The output is a navigable network of citation links, in which the user can identify the main players, taking into account the contribution of the balance/imbalance information.

\section{Triples extraction method for identify patent thicket}

To extract the information about the possible presence of patent thicket in a technological domain related to a patent application, we suggest a modified triples evaluation algorithm.

It works in a patent pool selected in a more refined way than OST-INPI/FhG-ISI (or NACE) classification, considering the reference application field only. Thereby the measure of thicket density is 'local' and the approach can index the main players involved in thickening.

The algorithm gives three different indexes about the triple inner imbalance.

First it shows the number of citations for each couple in both directions (see Fig. 2). This might unveil that one (or two) of the player involved in the triple is not effectively disturbing the other two because its blocking patents are limited in number. Therefore, the other two applicants might not actually worry about the triple and control the market as a duopoly (or monopoly). 


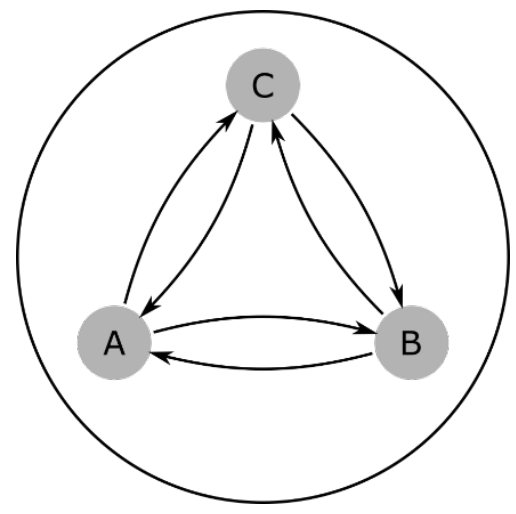

Fig. 2. A generic triple schema showing all citation relationships between the players. The arrows start from the cited player and go to the citing one (blocking direction).

The second index refers to the inner relative strength due to the portfolios size comparison of the triple players. The triples with an important imbalance due to this reason may suffer the effect of dominant positioning of one (or two) player. Thus, the actual configuration of the thicket tends to become a monopoly (or duopoly).

The last index measures the ratio between the target-technology-related portfolio of a firm in the triple and its whole patent portfolio. It indexes which is the effective interest of a single player involved in the triple to the target technology, and its relative market. A high ratio means the player considers strategic the target technology and the involving in triples could be a great fail risk.

The second index gives us the information about the inner imbalance between the players in a triple, while the third index shows the importance/interest of the target technology for each player (see Fig. 3).

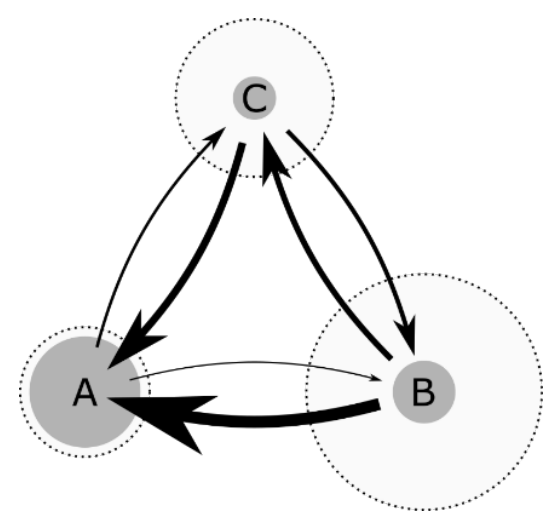

Fig. 3. A visualization of the imbalances inside a triple. The arrow thickness indexes the weight to the bilateral citation relationship, starting from the blocking player and pointing to the blocked one. The dotted circles indicate the dimension of the patent portfolios, related to the target technology. The number of the documents involved in the triple is proportional to the area of the grey circle. 
The assessment on potential imbalance in triples is a useful indication that could be integrated into the BI tools in order to unveil the actual structure of the market to the decision makers and let them to make choices in a more informed way.

Fig. 4 shows the algorithm used to compute the triples, considering filters in the choice of patent documents, application activity of the firms and inner imbalance in the triples.

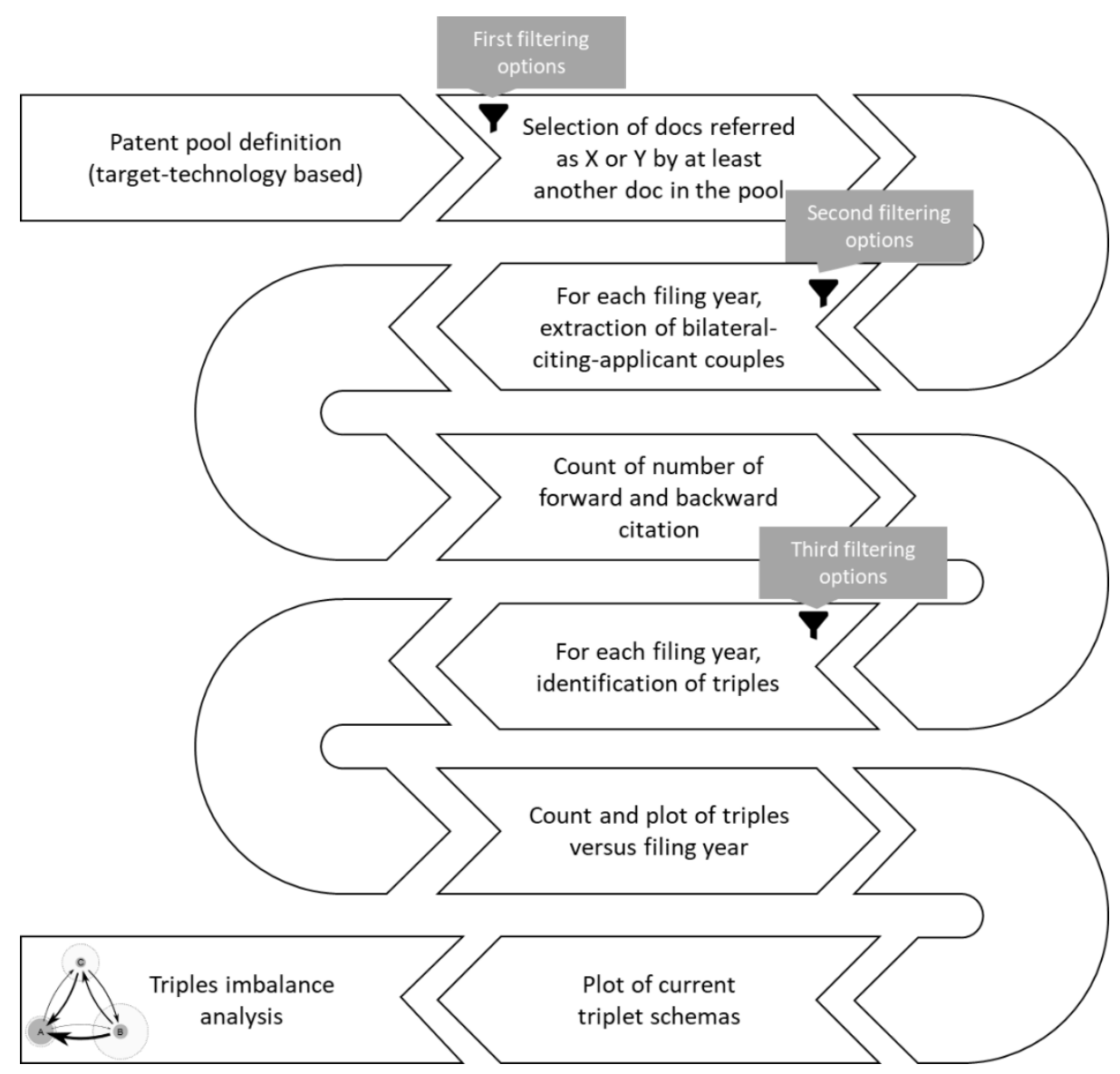

Fig. 4. The algorithm for the extraction from a technology-based patent pool of triples and related data. The first filtering option filters documents by filing year and applicants by minimum number of applications [10]. Second filter acts on the lifetime (in years) of a bilateral citation [10]. Filter 3 considers the imbalance parameters (relative portfolios dimension, documents involved in triple and number of bilateral citations)

As an example of the application of our proposed method we present the case of a pool of patent extract from Machine Learning patent field, and due to possible time lags in the patent office register update, we censor the last two years as suggested by the patent literature. We extracted all patents from Google, IBM and Microsoft focus- 
ing on machine learning and artificial intelligence. From Figure 5 we can observe this market segment is dominated by the presence of three major players, Google, IBM, and Microsoft Technology. We use citation as a measure of a patent market value [21], and in particular number of co-citation to identify the extent of the patent thickets among the major players. It emerges clearly that both Google and IBM tend to interact and make citation in a reciprocal relationship mainly with Microsoft Technology Licensing. Whereas the co-co-citation numbers between Google and IBM drop by almost 30 per cent compare to the same measure they have with Microsoft Technology. From this scenario it looks like that Microsoft Technology Licensing play a role as a leader controlling the number of citations which the other two players. This very preliminary analysis would suggest an oligopoly given the presence of three firms (with other two very small), where the one which owns the larger number of patents might play an important role in controlling the market entrants. Of course, a furthermore details analysis is needed to be able to understand if any illegal behaviour is in place (i.e. collusion). However, from this simple picture would it be already enough to confirm the presence of high barriers to entry which could discourage the progress of this specific technology, leaving if in the hands of few actors.

\section{Conclusions}

Due to the influence the competitiveness level might exert onto the success/failure of an inventive solution, its assessment is an important and strategic information for innovation activities.

This article gives to TRIZ experts a new tool that aims to assess the competitiveness level of the reference market. Using quantitative data from patents in the target technology field, the tool supports the choice of the innovation strategy for a firm that is looking for a new technology, especially when it operates in a complex market.

Although an economical research would be more accurate than the proposed method, the latter is very cheaper. In fact, while the first needs a high expertise in both economics and patents, the proposed method can run on currently available patent searching tools. This allows the TRIZ experts to carry out this analysis by themselves. Whether the result would be highlight a critical situation, a deeper analysis would be appropriate.

The method extracts citations data from patent database in order to compute triples and measure their inner balance. A great relative difference might highlight a dominant position.

It has been tested in machine learning field and it shown a dominant positioning of Microsoft, IBM and Google. The experimentation proves and highlights the risk for an unaware entrant to incur in unexpected extra charge due to the hard licensing bargaining.

The method is valid for any technical domain involved in patents. 


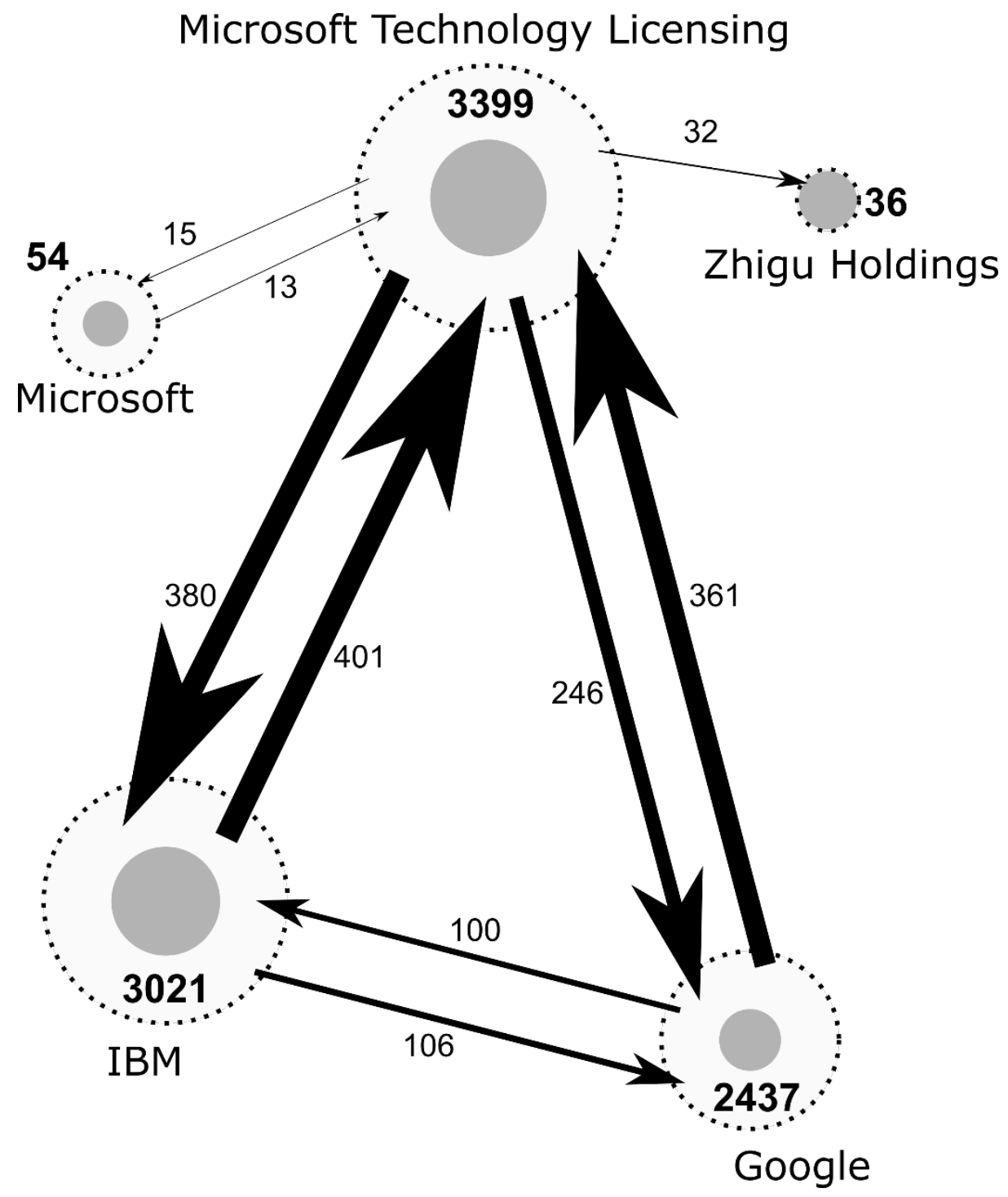

Fig. 5. Most interesting triple isolated by the algorithm in Machine Learning sector involving Google, IBM and Microsoft. The numbers near the circles indicate the number of patents held by the firm, while number on arrows shows blocking patents (or cited patents): e.g. IBM cited Google 100 times. 


\section{References}

1. Brannon N (2010) Business Intelligence and E-Discovery. Intellect Prop Technol Law J 22:1-5

2. Alaskar T, Poulis E (2015) Business Intelligence Capabilities and Implementation Strategies. Int J Glob Bus 8:34-45

3. Marchand M, Raymond L (2008) Researching performance measurement systems. Int J Oper Prod Manag 28:663-686 . doi: 10.1108/01443570810881802

4. Walsh JP, Lee Y-NN, Jung T (2016) Win, lose or draw? the fate of patented inventions. Res Policy 45:1362-1373 . doi: 10.1016/j.respol.2016.03.020

5. Livotov P (2014) Using patent information for identification of new product features with high market potential. In: TRIZ Future Conference. Elsevier B.V.

6. Arora A, Fosfuri A, Gambardella A (2001) Markets for Technology and their Implications for Corporate Strategy. Ind Corp Chang 10:419-451 . doi: 10.1093/icc/10.2.419

7. Shapiro C (2001) Navigating the Patent Thicket: Cross Licenses, Patent Pools, and Standard-Setting. In: Jaffe AB, Lerner J, Stern S (eds) Innovation Policy and the Economy. MIT Press, pp 119-150

8. Von Graevenitz G, Wagner S, Harhoff D (2011) How to measure patent thickets-A novel approach. Econ Lett 111:6-9 . doi: 10.1016/j.econlet.2010.12.005

9. Ijichi T, Yoda T, Hirasawa R (1994) Mapping R\&D Network Dynamics: Analysis of the Development of Co-author and Co-inventor Relations. J Sci Policy Res Manag 8:263-275 . doi: 10.20801/jsrpim.8.3_4_263

10. Von Graevenitz G, Wagner S, Harhoff D (2013) Incidence and growth of patent thickets: The impact of technological opportunities and complexity. J Ind Econ 61:521-563 . doi: 10.1111 joie. 12032

11. Rubinfeld D, Maness R (2004) The strategic use of patents: implications for antitrust. Antitrust, patents Copyr - EU US Perspect 85-102

12. Sabety T (2004) Nanotechnology Innovation and the Patent Thicket: Which IP Policies Promote Growth. Albany Law J Sci Technol 15:

13. Bawa R, Bawa SR, Maebius SB (2005) The nanotechnology patent "gold rush." J Intellect Prop Rights 10:426-433

14. D'Silva J (2009) Pools, Thickets and Open Source Nanotechnology. Eur. Intellect. Prop. Rev. 31:300

15. Clarkson G, DeKorte D (2006) The problem of patent thickets in convergent technologies. Ann N Y Acad Sci 1093:180-200 . doi: 10.1196/annals.1382.014

16. Hargreaves I (2011) Digital Opportunity

17. Hall B, Helmers C, von Graevenitz G (2015) Technology Entry in the Presence of Patent Thickets. Cambridge, MA

18. Galasso A, Schankerman M (2010) Patent thickets, courts, and the market for innovation. RAND J Econ 41:472-503 . doi: 10.1111/j.1756-2171.2010.00108.x

19. Gallini N (2017) Do patents work? Thickets, trolls and antibiotic resistance. Can J Econ 50:893-926 . doi: 10.1111/caje.12312

20. OECD (1994) The Measurement of Scientific and Technological Activities Using Patent Data as Science and Technology Indicators. OECD Publishing

21. Hall BH, Jaffe AB, Trajtenberg M (2005) Market Value and Patent Citations. RAND J Econ 36:16-38 . doi: 10.1007/s00216-009-2643-x 